\title{
“No Peeing on The Sidewalk!": Family Literacy Programs in Culturally, Linguistically, and Socially Diverse Communities
}

\author{
Jim Anderson \\ Ann Anderson \\ The University of British Columbia \\ Canada
}

\begin{abstract}
The purpose of this article is to reflect on three decades of working in family literacy initiatives in diverse communities. We review the literature on children's emergent early literacy development and family literacy and describe the conceptual framework, including socio-cultural theory, cultural models of learning and ethnotheories, culturally responsive pedagogy, and bilingualism and first or home language maintenance. We also describe the development and evolution of the various projects and their contexts after which we share some of the key things we learned from working with families and communities, including challenges. In conclusion, we highlight key insights garnered from this body of work for various stakeholders including teachers.
\end{abstract}

Keywords: family, diversity, culture, family literacy, early literacy, bilingualism, first language, families, culturally responsive pedagogy 
It is an unusually bright and sunny day in February and our colleague Fiona Morrison is leading a group of about 15 parents and other adult caregivers, their 4-and 5-year-old children, and their teacher on an environmental print walk near their inner city school. The walk is part of the session devoted to Environmental Print in a family literacy program called Parents As Literacy Supporters, that Jim Anderson and Fiona Morrison developed collaboratively with parents, early childhood educators, and community leaders nearly two decades ago. An experienced and talented early childhood educator, Fiona is exemplary in how she draws the children's attention to print, gets them to attend to the context, and try to determine what the print on the sign "says" and means. We have been all around the neighborhood, identifying signs and notes in store windows, (e.g,. "For Sale" and "For Rent" signs, street names and so forth), when she points up to the sign $(3)$ on a pole near the sidewalk just outside the main door of the school. Without any prompting, 4-year-old Jason (pseudonym) makes his way to the front of the group excitedly calling out, "Fiona, I know what that sign means! No peeing on the sidewalk!"”

In this paper, we reflect on three decades of working in family literacy programs in diverse contexts, including socially disadvantaged rural and urban communities and with immigrant and refugee families. We first attend to the research and scholarship that informed the development and implementation of these programs including: emergent and family literacy, cultural models of learning, culturally responsive education, funds of knowledge, and bilingualism and home language maintenance. Next, we briefly describe the various initiatives in which we were involved and some of the salient outcomes. Then, we share some of the challenges that we encountered, as well as some of the positive lessons that we learned from families and implications for teachers in working with families in culturally and socially diverse backgrounds.

\section{Background}

Over the last half century or so, studies have consistently shown that young children develop knowledge about literacy prior to formal instruction in school or preschool (e.g., Clay, 1972; Ferreiro \& Teberosky 1982; Flewitt, 2014). Young children's emerging knowledge, such as the understanding that print carries meaning, which 4-year-old Jason demonstrated in the opening vignette above, is considered foundational (Purcell-Gates, 1996) and predicts literacy achievement in school (Storch \& Whitehurst, 2002). Over the years, researchers working in culturally, linguistically, and socio-economically diverse communities have documented the important role of the family in encouraging and supporting children's early literacy development (e.g., Anderson, 1994, Su, 2017; Taylor, 1983; Taylor \& Dorsey-Gaines, 1988). Virtually all children growing up in literate societies see their parents and other family members engaging in literacy events at home and in the community. However, there are important differences in terms of the frequency of these literacy events, their functions and purposes, and how parents and significant others mediate children's literacy learning (Heath, 1983), even within the same cultural (Li, 2016) or socio-economic group (Purcell-Gates, 1996).

Based on the research showing the important roles that families play in children's early literacy learning and the strong positive correlation between children's early literacy knowledge and achievement at school, in the 1980s educators began developing family literacy programs to assist parents in supporting their children's learning. Although these programs appeared to be 
well intentioned, they soon came under powerful critique. Critics saw them as: favoring the dominant language (e.g., English) at the expense of families' home languages; ignoring vernacular literacy practices and promoting a narrow band of skills to prepare children for school; and positioning immigrant, refugee, and poor families in deficit ways (Auerbach, 1989; Tett \& Crowther, 1998).

Some program developers paid attention to these critiques and began developing programs that were socio-culturally responsive. As well, educators began developing bilingual family literacy programs, aimed at supporting children and families to maintain their first languages while also supporting them in acquiring or learning language and literacy in the dominant or official language of the local context. (Anderson, Friedrich, \& Kim, 2011; Hirst, Hannon, \& Nutbrown, 2010; Quadros \& Sarroub, 2016; Rodriguez-Brown, 2008; Singh, Sylvia, \& Ridzi, 2015; Zhang, Pelletier, \& Doyle, 2010). In general, these programs have a positive impact on children's early literacy development, and adult family members benefit from them (Swain, Brooks, \& Bosley, 2013). The programs that we describe in this paper reflect these social contextual principles. Before reflecting on and sharing insights from working in culturally responsive and bilingual family literacy programs in different contexts, we first describe the conceptual and theoretical frameworks that have shaped our work.

\section{Framework}

We draw on Vygotsky (1968) and other socio-cultural theorists who see learning as social, whereby more competent others support novices in learning the knowledge and skills that are important within their cultural context. Furthermore, there are significant cultural differences in how learning is supported (Wertsch, 1998). As Rogoff (2003) points out, research and scholarship in child development and learning have tended to reflect Eurocentric, middle-class orientations and perspectives. However, researchers and scholars (LeVine \& White, 1986) argue that people from different cultural groups have different "cultural models" of learning. For example, shared story book reading plays an important role in acculturating children into reading in some cultural groups, while in others parent-child shared book reading is not practiced (Brooker, 2003). Relatedly, some researchers suggest that families raise their children according to ethnotheories. Harkness and Super (1992) describe ethnotheories as beliefs and practices "embedded in the experiences of daily life that parents have with their own children at particular ages, as well as being derived from the accumulated cultural experience of the community or reference group" (p. 374).

Recognizing the diverse ways that children's development and learning are supported at home, educators have identified the pressing need for culturally responsive curriculum and pedagogy in schools (Kim \& Slapac, 2015). Culturally responsive pedagogy pays attention to children's and families' funds of knowledge, which Moll, Amanti, Neff, \& González, (1992) define as the "historically accumulated and culturally developed bodies of knowledge and skills essential for household or individual functioning and well-being" (p. 133).

Finally, in our work with immigrant and refugee families, we draw on scholarship in bilingualism, second language acquisition and home language maintenance and loss. We identify the following principles from this literature: 1) young children's language and learning in a second language is facilitated if their first language is intact (Snow, Griffin, \& Burns, 1998); 2) cognitive and linguistic skills transfer across languages (Cummins, 2013); 3) bilingualism offers cognitive and other benefits across the lifespan (Bialystok et al., 2016); and 4) intergenerational family communication is enhanced when children maintain their first or home language (Wong- 
"No peeing on the sidewalk!": Family literacy programs

Fillmore, 2000). Put simply, there are compelling reasons to work with immigrant and refugee families in family literacy programs in maintaining their home languages. Having outlined these conceptual underpinnings, we now describe family literacy projects in different contexts in which we worked.

\section{The Community Contexts: What We Did}

\section{A Rural Village: The "Early Intervention" Program}

Despite the title, which bespeaks a deficit orientation, this initiative was organic or bottom-up in that the idea to develop the program originated in a rural, economically depressed village in eastern Canada in the late 1980s. The principal of the community school, who was born and raised in the village and still lived there, approached the local school district with the idea of providing support for preschool children's learning and literacy development. He drew on longitudinal data to show that: 1) many of the children who left the school after grade 9 did not graduate from the local regional high school; 2) the children consistently scored below average on achievement tests that the province and the school district administered; 3) an above-average number of students were identified as needing remedial programming; and 4) many former students were unemployed or worked in low-paying jobs (Anderson, Norman, \& Anderson, 2008).

One of the authors, who was an assistant superintendent with the regional school board, worked closely with and supported the district's early childhood education coordinator and the kindergarten teacher who led the development of the program and implemented it. During the development stage, they consulted with families, community leaders, health and social service workers in the area, other educators, and of course, the extant literature on early childhood education and family engagement. The program consisted of a series of half-day sessions in which a parent or significant adult accompanied the preschoolers to school. The early childhood coordinator and the kindergarten teacher demonstrated and modeled various resources and strategies (e.g., sand and water play; finger painting; dialogic shared book reading) and encouraged the adults to interact with their children at various learning centers in the kindergarten classroom. To conclude each session, the facilitators provided the families with a high-quality picture book. The second author lived in the community and attended sessions as a parent with her preschooler and served as a volunteer at times.

\section{Inner-City Neighborhoods: Community Centers}

The second initiative involved a collaboration with community centers located near public housing projects in two inner city areas of a relatively small urban region in eastern Canada in the mid 1990s. (Anderson, Fagan, \& Cronin, 1998). Sessions were held in the community centers since the families indicated they would feel more comfortable there than they would at the schools their children attended, since many of them had unpleasant memories of their own experiences at school. Sessions were two hours, and the parents and other significant adults attended. The program drew on Hannon's (1995) ORIM model, in which parents learn how they might: provide Opportunities for children's learning, Recognize children's literacy engagement, Interact with children, and Model literacy engagement and learning. Parents learned how they could apply the strategies by using materials at home and in the community (e.g., environmental print) and through daily routines (e.g., shopping; walks in the neighborhood). 


\section{Inner-City Neighborhoods: Community Schools}

This project started in 1999 when the mayor of a small city in Western Canada invited the author J. Anderson and Fiona Morrison, the early learning coordinator from the local school district, to participate in a community development initiative in two inner-city community schools by developing an early literacy program. The mayor believed that the program would give the children a head start when they entered school. The developers held focus groups with families, educators, and administrators and, drawing on these discussions and their previous experiences, Anderson and Morrison developed a series of sessions, which they piloted in both schools, modified according to feedback from the families, and then offered over the course of a full year. The Parents As Literacy Supporters (PALS) program (Anderson \& Morrison, 2000) consisted of 10-12 two-hour sessions, offered at the community schools at times convenient for the families. Each included eating together, adult alone time, parent-child together time, and adult debriefing. Topics included learning to read, technology and young children, early mathematics, and so forth. Facilitators provided each family with a package of materials such as construction paper, markers, dice, scissors, and so forth, and at each session they provided each child with a high-quality picture book to take home and keep.

Word of the program spread and other communities and schools indicated a desire to implement the program. We developed a two-day professional development institute for facilitators and wrote a manual, which provided the rationale and background of the program, key principles, and sample outlines of sessions, but that emphasized the need to adapt and adopt to fit the local context.

\section{Immigrant and Refugee Communities}

In the three-year PALS in Immigrant Communities project (2007-2010), we worked with more than 500 immigrant and refugee families in five communities in a large urban area of western Canada. In this bilingual program, which maintained essentially the same structure as the PALS program just described, an early childhood educator and a cultural worker offered sessions in English and in the first language (L1) of the families (Farsi, Karen, Mandarin, and Punjabi). We translated all of the materials into the L1 of the families in each community and provided the families with a dual language book at each session. We revised the two-day professional development institute to focus on issues such as first language maintenance, culturally appropriate pedagogy, working with immigrant families, and so forth; we also provided twice yearly one-day professional development sessions over the three-year development and implementation stage.

\section{What We Learned}

Having briefly described the different projects in differing contexts, we next report what we learned from three decades of working with families from diverse backgrounds.

\section{Community Collaboration}

A key element in each of the projects described above is that the local communities identified a need and then we worked collaboratively with community members to develop a program that fit the aspirations and goals of the community. For example, in the rural village on the east coast, community members believed that helping children develop school readiness was a central goal so that children would successfully transition into school. On the other hand, the 
immigrant and refugee communities held different goals as they saw helping families become familiar with and comfortable in school, helping children and families learn English, and familiarizing families with western education and pedagogy as parallel goals. Of course, as we worked with communities and families, we also drew on the extant literature in areas such as culturally appropriate pedagogy, early childhood development and learning, family literacy, first and second language acquisition and learning in an attempt to ensure our efforts reflected best practices.

\section{Contextual Responsiveness}

Over the years, scholars (Auerbach, 1989; Janes \& Kermani, 2001) have stressed the need for family literacy programs to be responsive to the local context, and we have attempted to maintain this stance in our work. For example, we negotiated with families and communities in terms of the locations and formats of the program, the days and times when the programs were scheduled, and what the programs "looked like." As indicated, one of the programs was run out of two community centers located in socially disadvantaged neighborhoods because some of the families indicated that they would feel uncomfortable in a school, due to their own negative experiences as students. Likewise, when we worked with immigrant and refugee families, we scheduled sessions for times that worked best for the families: first thing in the morning at one of the sites, mid-day at two of the sites, late afternoon at another, and in the case of one site, early evening. We also adapted the program to fit the needs of the community. For instance, when we worked with Vietnamese families, we added an adult English-as-an-additional-language component because the adults wanted to improve their reading and writing skills. The next year, the adults at that site indicated that they wanted to learn about "computers" so we added a digital technology component for them employing Grade 7 Vietnamese speaking students as teaching assistants, which we ran back-to-back with the family literacy component (Perkins, 2010).

\section{Assessment and Evaluation}

One of the criticisms of family literacy programs over the years is that there is often a lack of assessment or evaluation (Hannon, 2010). Like Swain, Brooks, and Bosley (2013), we believe that it is essential to hear from parent participants in family literacy programs. For example, Anderson and Morrison (2007) asked participants at five sites to write anonymously and voluntarily in response to an open ended prompt "Parents As Literacy Supporters (PALS) was...." Although in general the families responded positively about the program, indicating that they valued the Parent-Child together time, appreciated learning about early literacy strategies and resources, and developed social networks, they also indicated that they were unsure about how to use some of the resources such as wordless picture books. Likewise, some respondents did not see the relevance of the environmental print walk. From these assessments, we realized that we needed to be more explicit and explain the purposes of various activities and resources to the families. In the project with the immigrant and refugee families, we conducted focus group sessions in the families' first languages, just after the midpoint of the program. We used the feedback from families in a formative manner and were able to make necessary adjustments. As noted earlier, during the last half hour of each PALS session, we debriefed with the adults, providing prompts such as: what did your child learn, what did your child enjoy most, what did not work well, and so forth. It came to light through a cultural worker at one of the debriefings that some of the families were unsure of the purposes behind a session on oral language that we called "Riddles, raps and rhymes." We subsequently explained how playing with language 
supports children's developing phonological awareness, which is an important skill in learning to read alphabetic languages such as English.

Of course, we also realize that families who attend these programs expect their children to acquire the early literacy knowledge that will enable their learning at school. Furthermore, not all early literacy programs "work;" indeed, as Phillips, Norris and Steffler (2007) document in their study of an intervention program in inner-city schools in an urban area of Canada, children's literacy learning appeared to be negatively impacted by their participation in it. Cognizant of these perspectives, in the project with immigrant and refugee children, we used an age appropriate Test of Early Reading Ability Test -2 (Reid, Hresko, \& Hammill, 1989) as one component of the mixed methods design to demonstrate that the children made significant gains over the course of the program (Anderson, Friedrich, \& Kim, 2011). We were able to reassure the parents, the program facilitators, and the agency funding the program that children were learning the foundational knowledge and skills that are predictive of later success in literacy learning in school.

\section{Developing Social Capital}

Although much of the focus in family literacy has been on children's literacy development, we have observed benefits to the adults as well. For example, the families in the "early intervention program" indicated that they had developed social networks through their participation in the program. Some of them indicated that they started volunteering in their children's classrooms and became involved in the school in other ways. An Indigenous father who participated in the PALS program in a rural area of British Columbia told of how his involvement helped him to develop a level of comfort in the school and to approach the teachers and staff when he had questions or concerns (Anderson, Morrison, Leighton-Stephens, \& Shapiro, 2007). He explained that his grandparents attended one of the infamous residential schools, where Indigenous children were taken from their home communities often against the will of their families, prevented from speaking their home languages and practicing their culture, and in many cases, provided with a substandard education (Hare, 2005). That legacy and his own negative experiences as a student had led him to be apprehensive about, and to avoid involvement in, schools. Encouraged by the Indigenous facilitators and other families attending the PALS sessions, he developed a level of comfort being in, and more fully participating in, school, advocating for his children and so forth.

Families also told of how they became more confident in participating in school events and organizations such as school councils and parent-teacher organizations. For example, Cody (2005) wrote about her experiences in the PALS program offered in her community school and how the affirming, non-judgmental atmosphere there helped develop her self-confidence, and she assumed leadership positions in the parent-teacher organization. Many of the families we worked with live "on the margins" as it were. Laureau (2003) and others have documented how workingclass families and others who are marginalized tend not to feel comfortable in schools and not to participate in school affairs. She suggests that middle- and upper-class families have the social and cultural capital (Bourdieu,1991) that schools value and which facilitates their participation and involvement there. On the other hand, working-class families and immigrant and refugee families, who do not share the same cultural and social capital, often feel alienated (Laureau, 2003). Families' participation in schools and in their children's education is positively related to their academic achievement (Epstein, 2011). Thus we believe that through these various 
"No peeing on the sidewalk!": Family literacy programs

initiatives we supported families in developing the social capital that allowed greater participation in their children's education.

\section{Challenges}

Although we have identified benefits and positive results of our work in diverse communities over the years, there have also been various challenges. We next discuss a number of these.

\section{Recruitment}

Participation in the various programs has been voluntary, and for example, we did not work with social service agencies or health care providers in recommending potential clients. That is, we wanted families to attend of their own volition and not feel coerced in any way to attend. Over the years, we have used various recruitment strategies, including school and school district newsletters, advertisements in community newspapers, posters and flyers in the community and so forth. However, many participants have indicated that they learned about the program through word of mouth. When we work in culturally and linguistically diverse communities, we attempt to use bilingual signs and notices and involve cultural workers from the community in designing them. Although in more recent years, social media such as Facebook likely assisted recruitment efforts, we believe that there are still unresolved issues. For example, we have had participants join the program halfway through the year because they had only just then heard about it. Participants have told us that they believed that there were other families in their neighborhood, who did not attend but would have benefitted. It might be that more active strategies such as having cultural and community workers contact families directly are necessary. Indeed, other community leaders can also assist; for instance, in the rural community described above, the local parish priest was supportive of the "early intervention" program and promoted it during church services, by announcing the day and time for upcoming sessions, and so forth.

\section{Continuity and Program Fidelity}

Although it might seem contradictory to discuss program fidelity in programs that are contextually responsive, we believe that some principles that inform our work are inviolable. As mentioned, a central tenet of our work is that families hold different cultural models of learning and have different ethno-histories and indeed, we have documented how these are enacted within the PALS program (Anderson \& Morrison, 2000). We shared and discussed our findings with program facilitators as we worked alongside them. However, over the years, facilitators continued to express concerns; for example, that some parents do not allow their children to experiment with materials first, but model how to complete an activity for the child before allowing him or her to attempt it on his or her own. They were also concerned that some parents, emulative of the non-Anglo families in Brooker's (2003) study in the U.K., did not engage with their children in play and did not see it as an appropriate role to become involved. Indeed, some facilitators saw parents' enactment of different cultural models (LeVine \& White, 1986) or ethnotheories (Harkness \& Super, 1992) as challenging their own firmly held beliefs about childcentered pedagogy and requested suggestions as to how they can shift parents actions to align with this philosophy (F. Morrison, personal communications).

As noted, when we worked with the immigrant and refugee families, we were committed to a bilingual program where families' first languages and English had equal status. That is, we wanted to promote first language maintenance through what we did, not just what we said. We 
devoted considerable attention to this issue in the initial professional development days and in the ongoing professional development sessions. For example, we provided the facilitators with relevant readings from the professional and research literature and discussed the implications for the work we were doing with families. Despite these efforts, we noted that at some sites, the bilingual agendas for each session, which demonstrated the value of families' first languages, began to disappear and be replaced with English only versions. In other cases, facilitators shared bilingual books with the families as a culminating activity in sessions but read only the English version (Friedrich, 2016), which was inconsistent with the intent of the program.

\section{Resources}

Because many of the families with whom we have worked have limited financial resources, we have always provided materials such as books, drawing/writing materials, dice, and playing cards to take home. We have encountered several issues in terms of resources. For example, when we worked in the inner-city community centers, we provided the families with Play-doh kits that we bought on sale. However, some of the families complained that they had to stop allowing the children to use it because they had gotten some of it into the carpet. The parents reported that the Social Housing Authority from whom they rented their apartments regularly inspected their homes and stains or spots on the carpet would cause difficulties for them. Although we were able to obtain dual-language texts for most of the families in the PALS in Immigrant Communities project, we were not able to find books in Karen and English. The Karen cultural worker made overlays to paste into the books but the task of preparing books for each family for each session was labor intensive, costly, and likely unsustainable in the long term. Finally, there is a lack of culturally appropriate children's books in some communities; for example, there are very few children's books written by Indigenous authors from which to choose.

\section{Sustainability}

As is the case with many family literacy initiatives, sustainability was a constant issue because there is seldom long-term funding provided for them. For example, in the case of the PALS project, although the school district and the two schools initially provided some start-up funding, to keep the program running in subsequent years, Fiona Morrison and the facilitators resorted to various fundraising efforts such as running raffles in the local shopping mall. In the case of our work with Immigrant and Refugee Communities, we are fortunate in that a nonGovernmental agency has assumed responsibility for supporting the program. They have been able to secure grants from Government of Canada departments and agencies responsible for the settlement of new immigrants and have expanded the program to other languages and in other communities. Nevertheless, this funding is year-to-year and contingent upon grant applications and considerable, time consuming, bureaucratic accountability (Aliza Dhungana, personal communications).

\section{Implications for Teachers}

We believe there are several implications for teachers that arise from this work. First, it is essential that teachers get to know as much as possible about the communities in which they work, as well as the families whose children they teach. For example, if parents and significant others in families have low literacy skills, asking them to "read to your child every day" is likely 
pointless. Promoting oral storytelling or simply talking with children about everyday events may be more appropriate. Likewise, if families are unfamiliar with dialogic or interactive shared book reading, which is what we really mean families to do when we ask them to read with their child, teachers need to model for families, what this "looks like" in practice. It is also important that educators recognize that families bring with them their own beliefs about learning and teaching. For example, some families will not see value in learning through play and at home, will have their young children engage in copying the letters of the alphabet for example or engage in rote memorization. It is important that teachers understand these as historical, cultural practices and not denigrate them, while at the same time, sharing with families in positive ways activities that they regard as more developmentally appropriate.

Teachers can also demonstrate to families the value of first language maintenance, for example, by using dual-language resources in their classrooms. They can also help families understand the value of maintaining their home language, since some parents are concerned when they do not use English (or the dominant language) with their children, even when they have limited facility with it. Perhaps one of the key things that teachers can do is to make families feel comfortable and welcomed in school. This was a major goal of all of the initiatives described, and across the different contexts families repeatedly told us that they felt comfortable and welcomed. Indeed, we have found that the families we worked with often start to participate more in school affairs, volunteering in classrooms or taking on leadership roles, as was the case of Stacey Cody mentioned earlier (Cody, 2006). We see a need for teachers to be flexible when working with families. For example, in many families, both parents work, sometimes holding down two jobs. Therefore, grandparents, aunts or uncles, or older siblings, may show up at "parents" night or parent-teacher conferences, especially if these occur during daytime working hours. Teachers could also consider scheduling events involving parents and caregivers outside the regular school day, as we did in some of the initiatives that we described. As well, given the ubiquity of mobile devices such as smart phones and tablets, teachers could also consider using "Fresh Grade" or similar electronic portfolio platforms to communicate with families more asynchronously to accommodate their schedules.

\section{Conclusion}

Looking across three decades of work in family literacy programs, several key points stand out. First, we propose that involving families and communities in developing the family literacy initiatives helps ensure that they were responsive to their aspirations and needs. As well, we sense that this involvement creates a sense of ownership in communities and greater buy-in by families. Second, this work indicates the need for ongoing formative assessment and evaluation so that adjustments and modifications can be made as necessary on an ongoing basis. Although much of the focus in family literacy programs has been on children's literacy development, parents and significant others who participate also indicate that they benefit in different ways. As well, family literacy programs such as Parents As Literacy Supporters in Immigrant Communities can help families from culturally and linguistically diverse backgrounds to recognize the importance of maintaining their home language and culture, while acquiring or learning the dominant language of their new communities. Finally, this work suggests the need to avoid a "one-size-fits-all" approach to family literacy. In an era of increasing accountability, centralization, and standardization, we believe this latter point is especially poignant.

Although the responses to the different initiatives were generally positive, challenges and concerns arose, as we have indicated. A couple of decades ago, Thomas and Skage (1998) 
indicated the need for program evaluation to move beyond what they saw as "testimonials" (p. 20). As the area of family literacy matures, we believe it is important for those involved in family literacy programs to identify challenges and issues that arise and to attempt to find solutions to them. 
"No peeing on the sidewalk!": Family literacy programs

\section{References}

Anderson, J. (1994). "Daddy, what's a picket?" One child's emerging knowledge of workplace literacy. Early Child Development and Care, 98, 7-20.

Anderson, J., Fagan, B., \& Cronin, M. (1998). Insights in implementing family literacy programs. In E. G. Sturtevant, J. Duggan, P. Linder \& W. Linek (Eds.), Literacy and community (pp.269-281). Commerce, TX: The College Reading Association.

Anderson, J., Friedrich, N., \& Kim, J. (2011). Implementing a bilingual family literacy program with immigrant and refugee families: The case of Parents As Literacy Supporters (PALS). Vancouver, BC: Decoda Literacy Solutions. Available at: http://www.decoda.ca/wpcontent/uploads/PALS-in-Immigrant-Communities-Research-Report-Feb-2011-2.pdf

Anderson, J., \& Morrison, F. (2000). The PALS Handbook: Creating and sustaining a Culturally Responsive Family Literacy Program. Langley: British Columbia Langley School District.

Anderson, J., Morrison, F., Leighton-Stephens, D., \& Shapiro, J. (2007, May). Listening to parents' voices: Working with First Nations communities in a culturally responsive family literacy program. Paper presented at the annual conference of the Canadian Society for the Study of Education, Saskatoon, SK.

Anderson, J., Norman, P., \& Anderson, A. (2008). Family literacy at St. Mark's School: Enhancing student achievement, building capacity, and developing social and cultural capital in rural Newfoundland. In D. Dibbon \& G. Galway (Eds.). Proceedings of Symposium 2008: Post-confederation educational reform- From rhetoric to reality. (pp. 1-9). St. John's, NL: Memorial University of Newfoundland.

Auerbach, E. (1989). Toward a social-contextual approach to family literacy. Harvard Educational Review, 59, 165-181.

Bialystok, E., Abutalebi, J., Bak, T. H., Burke, D. M., \& Kroll, J. F. (2016). Ageing in two languages: Implications for public health. Ageing Research Reviews, 27, 56-60.

Bourdieu, P. (1991). Language and symbolic power. Cambridge, MA: Harvard University Press.

Brooker, L. (2003). Learning how to learn: parental ethnotheories and young children's preparation for school. International Journal of Early Years Education, 11(2), 117-128,

Clay, M. M. (1972). Reading: The patterning of complex behavior. Auckland, New Zealand: Heinemann Educational Books.

Cody, S. (2005). A single mother's journey of rediscovery. In J. Anderson, M. Kendrick, T. Rogers, \& S Smythe (Eds.). Portraits of literacy across families, communities and schools: Intersections and tensions. (pp. 87-90). Mahwah, NJ: Lawrence Erlbaum Associates.

Cummins, J. (2013). BICS and CALP: Empirical support, theoretical status, and policy implications. In M. Hawkins (Ed.), Framing languages and literacies (pp.10-23). London: Routledge.

Epstein, J. (2011). School, family and community partnerships: Preparing educators and improving schools. Boulder, CO: Westview Press. 
Ferreiro, E., \& Teberosky, A. (1982). Literacy before schooling. Exeter, NH; Heinemann Educational Books.

Flewitt, R. S. (2014). Early literacy learning in the contemporary age. In J. Moyles. J. Payler, \& J. Georgeson (Eds.), Early years foundations: Critical issues (pp. 98-108). Maidenhead: Open University Press.

Friedrich, N. (2016). Making connections: Literacy practices of Karen refugee families in the home, community and family literacy program. Unpublished doctoral dissertation, University of British Columbia, Vancouver, British Columbia.

Hannon, P. (1995) Literacy, home and school: research and practice in teaching literacy with parents. London: Falmer Press.

Hare, J. (2005). To "Know Papers": Aboriginal perspectives on literacy. In J. Anderson, M. Kendrick, T. Rogers \& S. Smythe (Eds.), Portraits of literacy across families, communities and schools: Intersections and tensions (pp. 243-264). Mahwah, NJ: Lawrence Erlbaum Associates.

Harkness, S., \& Super, C. (1992). Parental ethnotheories in action. In I. Siegel, L. McGillicuddyDeLisi, and J. Goodnow (Eds.). Parental belief systems: The psychological consequences for children (pp.373-391). Hillsdale, NJ: Lawrence Erlbaum

Hirst, K., Hannon, P., \& Nutbrown, C. (2010). Effects of a preschool bilingual family literacy programme. Journal of Early Childhood Literacy, 10, 183-208.

Janes, H. \& Kermani, H. (2001). Caregivers' reading stories to young children in family literacy programs: Pleasure or punishment? Journal of Adolescent and Adult Literacy, 44, 458-466.

Kim, S., \& Slapac, A. (2015). Culturally responsive, transformative pedagogy in the transnational age: Critical perspectives. Educational Studies, 51, 17-27.

Laureau, A. (2003). Unequal childhoods: Class, race and family life. London: University of California Press

LeVine, R. \& White, M. (1986). Human conditions: The cultural basis of educational development. New York: Routledge \& Kegan Paul.

Li, G. (2016). Social class, culture and Asian children's home and school literacy connection: The case for cultural reciprocity in early literacy education. In J. Anderson, A. Anderson, J. Hare, \& M. McTavish (Eds.), The intersection of culture, language and learning in early childhood in the contexts of communities, families and schools (pp. 103-122). New York: Routledge.

Moll, L., Amanti, C. Neff, D., \& González, N. (1992). Funds of knowledge for teaching: Using a qualitative approach to connect homes and classrooms. Theory into Practice, 31(2), 132-141.

Perkins, S. (2010). PALS in Vietnamese: Implementing a bilingual family literacy program. In S. Szabo, M. Sampson, M. Foote, \& F. Falk (Eds.), Mentoring literacy professionals: Continuing the spirit of CRA/ALER after 50 years (pp. 81-93). Commerce, TX: Association of Literacy Educators and Researchers. 
"No peeing on the sidewalk!": Family literacy programs

Phillips, L., Norris, S., \& Steffler, D. (2007). Potential risks to reading posed by high dose phonics. Journal of Applied Research in Learning, 1(1), 1-18.

Purcell-Gates, V. (1996). Stories, coupons, and the TV Guide: Relationships between home literacy experiences and emergent literacy knowledge. Reading Research Quarterly, 3, 406428.

Quadros, S. D. M., \& Sarroub, L. K. (2016). The case of three Karen refugee women and their children: Literacy practices in a family literacy context. Diaspora, Indigenous, and Minority Education, 10, 28-41.

Reid, D., Hresko, W., Hammill, D. (1989). Test of Early Reading Ability-2. Texas: PRO-ED, Inc.

Rodriguez-Brown, F. (2008). The home-school connection: Lessons in a culturally and linguistically diverse community. New York: Routledge.

Rogoff, B. (2003). The cultural nature of human development. Oxford: Oxford University Press

Singh, S., Sylvia, M. R., \& Ridzi, M. (2015). Exploring the literacy practices of refugee families enrolled in a book distribution program and an intergenerational family literacy program. Early Childhood Education Journal, 43, 37-45.

Snow, C., Burns, M., \& Griffins, P. (Eds.). (1998) Preventing reading difficulties in young children. Washington, DC: National Academy Press.

Storch, S. A., \& Whitehurst, G. J. (2002). Oral language and code-related precursors to reading: Evidence from a longitudinal structural model. Developmental Psychology, 38, 934-947.

$\mathrm{Su}, \mathrm{M}$. (2017). The influence of early linguistic skills and family factors on literacy acquisition in Chinese children: Follow-up from age 3 to age 11. Learning and Instruction, 49, 54-63.

Swain, J, Brooks, G., \& Bosley, S. (2013). The benefits of family literacy provision for parents in England. Journal of Early Childhood Research, 12(1), 77 - 91

Taylor, D. (1983). Family literacy: Young children learning to read and write. Portsmouth, NH: Heinemann Books.

Taylor, D., \& Dorsey-Gaines, C. (1988). Growing up literate: Learning from inner city families. Portsmouth, NH: Heinemann Books.

Tett, L. \& Crowther, J. (1998). Families at a disadvantage: Class, culture and literacies. British Educational Research, 24, 449-461.

Thomas, A., \& Skage, S. (1998). Overview of perspectives on family literacy: Research and practice. In A Thomas (Ed.), Family Literacy in Canada: Profiles of Effective Practices (pp.5-24). Welland, ON: Soleil Publishing.

Vygotsky, L. (1978). Mind in society: The development of higher psychological processes. Cambridge, MA: Harvard University Press.

Wertsch, J. (1998). Mind as action. New York: Oxford University Press.

Wong-Fillmore, L. (2000). Loss of family languages: Should educators be concerned? Theory into Practice, 39, 203-210. 
Zhang, J., Pelletier, J., \& Doyle, A. (2010). Promising effects of an intervention: Young children's literacy gains and changes in their home literacy activities from a bilingual family literacy program in Canada. Frontiers of Education in China, 5, 409-429. 